\title{
Repetition of accidents in young children
}

\author{
C JANE EMINSON, ${ }^{1}$ HARJINDER JONES, ${ }^{2}$ AND MICHAEL GOLDACRE ${ }^{2}$ \\ From the Department of Social Medicine, ${ }^{1}$ University of Birmingham, and Unit of Clinical Epidemiology, ${ }^{2}$ \\ Department of Community Medicine and General Practice, University of Oxford
}

SUMmaRY Data from the Oxford Record Linkage Study have been used to describe rates of accident repetition for children aged under 5 years. As reflected by hospital admissions, accident rates for children who have already had one accident were approximately twice those of children of the same age and sex who had previously been accident free.

There has been much debate on the subject of accident repetition in general and repeated accidents to children in particular. The psychological and psychiatric literature, based on reports of case series, has provided the impetus behind this discussion, concentrating on particular personality characteristics of the child ('accident proneness') which combine with family and environmental factors to make him or her liable to repeated accidents. ${ }^{1-3}$ From an epidemiological perspective much of this work is easily criticised for lack of a control group, retrospective assessment of risk factors, and failure to realise that a random distribution of accidents would result in some children having more than others.

Two case-control studies found no difference between children admitted to hospital for head injuries and age and sex matched controls in their previous history of accidents as reported by parents. ${ }^{4}$ A study of in- and out-patient consultations for injuries found, however, that children aged 4 to 18 years with three or more injuries in one four year period had in the next four years average injury rates 75 to $100 \%$ higher than children who were accident free in the first period. ${ }^{6}$ This suggests that some children are at particularly high risk, although it has been shown that such associations are neither stable nor independent of the length of interval between periods. ${ }^{7}$ Two recent cohort studies have described child accident frequency but not published data on repeat accident rates specifically. Forty-four per cent of the 11981 children followed by the Child Health and Education Study had one accident (of any severity) before age 5 and $28 \%$ of these had two or more. ${ }^{8}$ Comparable figures from a New Zealand study of 991 births followed for five years are $49 \%$ having one accident and $33 \%$ of these experiencing two or more. ${ }^{9}$
Accident rates vary considerably with age during the first five years of life. ${ }^{9}$ The hypothesis that some children have a consistently high accident risk must therefore be tested by comparing rates of second (or more) accidents with first accident rates for children of the same age and sex. Hospital admission rates following childhood accidents have been declining rapidly in recent years; ${ }^{10}$ time-specific, as well as sexand age-specific rates therefore need to be studied. The linked data of the Oxford Record Linkage Study (ORLS) allow such comparisons to be made for hospital admissions following accidents. A cohort study is described comparing first and second hospital admission rates for accidents to children under the age of 5 .

\section{Methods}

The methods of collection and linkage of data for the ORLS have been described elsewhere. ${ }^{11}$ Hospital admissions with a discharge diagnosis indicative of an accident (coded N800 to N989 inclusive or N996) were selected for children aged under 5 born in 1971-73 and resident in the original ORLS area or West Berkshire DHA at the time of admission.

Person years at risk of a first accident at each age were calculated by assuming that all children born in Oxfordshire and West Berkshire were alive and still resident there until age 5 and then subtracting the time after deaths and first accidents when children (wherever they were born) were no longer at risk. Children were at risk of a second accident from the date of the first accident until the second accident, death or age 5, whichever came soonest. First and second accident rates were then calculated. Second accident rates were divided by first accident rates to give relative rates. These therefore compare the rate of hospital admissions for accidents among children 
who had previously been admitted following an accident with the rate among children of the same age and sex with no such admission previously recorded.

This approach assumes that migration in of children was equalled by migration out. There was actually a modest level of net in-migration of under 5 year olds to the area during the period studied. (In 1972 the estimated one year net migration of children aged 0 to 4 between Oxfordshire and the UK outside the Oxford Record Linkage area was 34 per 1000 for males and 37 per 1000 for females. ${ }^{12}$ ) If accidents were unrelated to migration, the overall migration trend would have affected person years at risk of first and second accidents to the same extent. Both rates would therefore be overestimates, but the relative rate should have remained the same. Migration will, however, have led to a few second accidents being classified as first ones (the first having happened outside the area) and some second accidents being missed. Thus the calculated second accident rates are underestimates. This effect will slightly decrease the relative rates which will therefore also be underestimated.

If some children are at a consistently high accident risk, their first accident rates would also be higher. Inclusion of these children would raise the first accident rates and artificially decrease the relative rate. A comparison was therefore also made of second accident rates against rates of first accidents excluding children who went on to have another (that is, including only 'non-repeaters'). For these 'non-repeater' rates person years at risk were calculated by excluding from the first accident years at risk those children who went on to have another (that is, excluding the repeaters' years at risk).

\section{Results}

The number of hospital admissions for accidents to children aged under 5 are shown in table 1 . The male second accident rates are significantly higher than the first accident rates at ages 0,1 , and 4 years (tables 2 and 3 ). The non-repeater rates are lower than the first accident rates, and the comparison of second accidents with these is significant at all ages in males. Female second accident rates are higher at all ages

Table 1 Number of accidents per child

\begin{tabular}{|c|c|c|c|c|}
\hline \multirow{2}{*}{$\begin{array}{l}\text { Number of accidents } \\
\text { per child }\end{array}$} & \multicolumn{2}{|l|}{ Males } & \multicolumn{2}{|c|}{ Females } \\
\hline & No. & $\%$ & No. & $\%$ \\
\hline 1 & 1069 & 93.4 & 820 & 94.5 \\
\hline 2 & 64 & 5.5 & 47 & 5.4 \\
\hline 3 & 10 & 0.9 & 1 & $0 \cdot 1$ \\
\hline 4 & 2 & 0.2 & 0 & 0.0 \\
\hline Totals & 1145 & $100 \cdot 0$ & 868 & $100 \cdot 0$ \\
\hline
\end{tabular}

Table 2 Male accident rates*

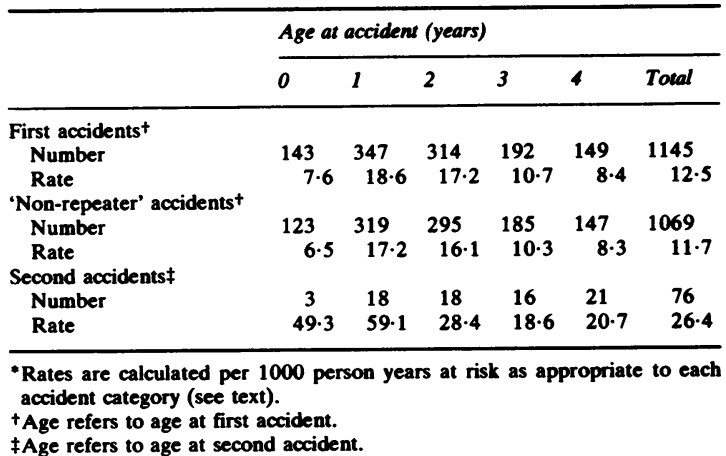

Table 3 Male age-specific relative rates

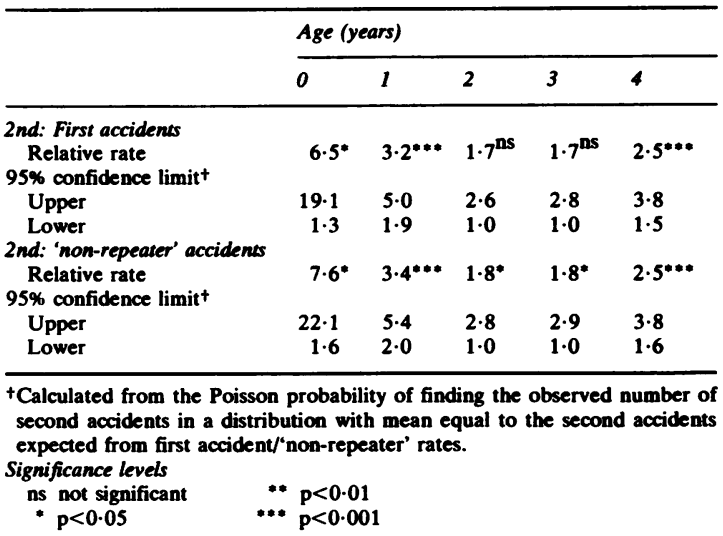

but significantly so only at ages 0,1 and 3 years (tables 4 and 5). The relative rates are raised for the same ages when the comparison is with non-repeaters. For both males and females the second accident rates are approximately seven times higher at age under 1 year, three times higher at age 1 , and twice as high from 2 to 4 years of age.

Study of repetition rates by type of accident would be interesting but was not possible because of the

Table 4 Female accident rates*

\begin{tabular}{|c|c|c|c|c|c|c|}
\hline & \multicolumn{6}{|c|}{ Age at accident (years) } \\
\hline & 0 & 1 & 2 & 3 & 4 & Total \\
\hline \multicolumn{7}{|c|}{ First accidents ${ }^{\dagger}$} \\
\hline $\begin{array}{l}\text { Number } \\
\text { Rate }\end{array}$ & $\begin{array}{c}150 \\
8 \cdot 3\end{array}$ & $\begin{array}{c}259 \\
14 \cdot 6\end{array}$ & $\begin{array}{c}219 \\
12 \cdot 6\end{array}$ & $\begin{array}{c}123 \\
7 \cdot 1\end{array}$ & $\begin{array}{r}117 \\
6.8\end{array}$ & $\begin{array}{c}868 \\
9.9\end{array}$ \\
\hline \multicolumn{7}{|c|}{ 'Non-repeater' accidents' } \\
\hline Number & 138 & 240 & 206 & 122 & 114 & 820 \\
\hline Rate & $7 \cdot 7$ & 13.6 & 11.8 & $7 \cdot 1$ & 6.6 & 9.4 \\
\hline \multicolumn{7}{|c|}{ Second accidents } \\
\hline $\begin{array}{l}\text { Number } \\
\text { Rate }\end{array}$ & $\begin{array}{c}4 \\
62.0\end{array}$ & $\begin{array}{l}10 \\
37 \cdot 8\end{array}$ & $\begin{array}{l}10 \\
10 \cdot 2\end{array}$ & 14 & 10 & 48 \\
\hline Rate & $62 \cdot 0$ & $\mathbf{3 7 \cdot 8}$ & & $21 \cdot 1$ & $13 \cdot 1$ & $21 \cdot 1$ \\
\hline
\end{tabular}


Table 5 Female age-specific relative rates

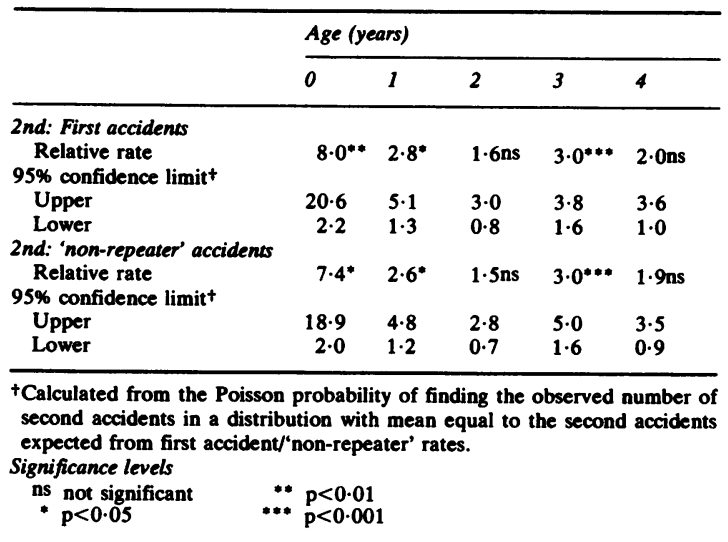

small numbers of poisonings and burns (table 6). Accident rates were broken down by calendar year. The second accident rates were then based on very small numbers, but within age groups, there was no consistent change over the years of the study in first or second accident rates. Secular trends in childhood accidents were therefore not considered further.

\section{Discussion}

This study has shown that children who have had one hospital admission for an accident are at approximately twice the risk of a repeat accident admission compared with children of the same age and sex with no previous admissions for accidents. These 'accident repeaters' also had higher first accident rates, indicating that their risk of accident was consistently raised. These findings corroborate those of Manheimer and colleagues even though their study referred to older children and to both inand out-patient consultations. ${ }^{8}$ Criticisms can, however, be levelled at the work concerning assumptions about migration, restriction to hospitalised accidents, and a general lack of utility.

Table 6 Types of accident

\begin{tabular}{|c|c|c|c|c|}
\hline \multirow[b]{2}{*}{ Accident type } & \multicolumn{2}{|l|}{ Male } & \multicolumn{2}{|l|}{ Female } \\
\hline & $\begin{array}{l}\text { First } \\
\text { accident } \\
\text { \% }\end{array}$ & $\begin{array}{l}\text { Second } \\
\text { accident } \\
\%\end{array}$ & $\begin{array}{l}\text { First } \\
\text { accident } \\
\%\end{array}$ & $\begin{array}{l}\text { Second } \\
\text { accident } \\
\%\end{array}$ \\
\hline $\begin{array}{l}\text { Injury } \\
\text { (N800-N939, N950-N959, N996) }\end{array}$ & 69 & 79 & 67 & 75 \\
\hline $\begin{array}{l}\text { Poisoning } \\
\text { (N960-N989) }\end{array}$ & 24 & 16 & 27 & 23 \\
\hline $\begin{array}{l}\text { Burns } \\
\text { (N940-N949) }\end{array}$ & 7 & 5 & 5 & 2 \\
\hline Totals & 100 & 100 & 100 & 100 \\
\hline $\mathbf{N}$ & 1145 & 76 & 868 & 48 \\
\hline
\end{tabular}

The influence of migration has been discussed. The overall effect will have been to decrease the relative rates. Departures from the assumption of independence of migration and accidents have not been considered but are unlikely to have had an impact sufficient to explain the increases in rates found here.

Only hospital admissions were studied. The raised second accident rates may therefore reflect admission policy or the parents' decision to take the child to hospital rather than the occurrence of accidents. It has been shown that factors predicting hospital admission for accidents differ from those predicting accidents in general. ${ }^{13}$ This study cannot separate policy and the 'incidence' of accidents, and it is possible that different presentation and admission practices could have led to relative rates of this order of magnitude.

The final criticism that has been raised concerning studies of accident repetition is lack of utility. ${ }^{14}$ Certainly attempts to identify the future accident repeaters at the time of their first accident would have an extremely low predictive value. It is also obvious that repeat accidents contribute little to the overall accident burden. However, children admitted to hospital after an accident have here been shown to be at higher risk of a subsequent accident admission. While acknowledging that a reduction in repeat accidents would have only a small public health impact, it seems pertinent to ask whether more advantage could be taken of the opportunity for preventive action offered by a first hospital admission for an accident.

Financial support to CJE through a Medical Research Council Advanced Course Studentship for the MSc in epidemiology course at the London School of Hygiene and Tropical Medicine is gratefully acknowledged. The Unit of Clinical Epidemiology is supported financially by the Department of Health and Social Security.

\section{References}

${ }^{1}$ Husband P. The accident-prone child. Practitioner 1973; 221: $335-44$.

${ }^{2}$ Attias D, Tal Y, Winter ST, Jaffe M. Hospital admissions following childhood accidents. Isr J Med Sci 1982; 18: 917-20.

${ }^{3}$ Padilla ER, Rohsenow DJ, Bergman AB. Predicting accident frequency in children. Pediatrics 1976; 58: 223-6.

${ }^{4} \mathrm{Klonoff} \mathrm{H}$. Head injuries in children: predisposing factors, accident conditions, accident proneness and sequelae. Am J Public Health 1971; 61 (12): 2405-17.

${ }^{5}$ Partington MW. The importance of accident-proneness in the aetiology of head injuries in childhood. Arch Dis Child 1960; 35: 215-23. 
${ }^{6}$ Manheimer DI, Dewey J, Mellinger GD, Corsa L. 50,000 child-years of accidental injuries. Public Health Rep 1966; 81: 519-33.

${ }^{7}$ Froggatt P, Smiley JA. The concept of accident proneness: A review. Br J Ind Med 1964; 21: 1-12.

'Taylor B, Wadsworth J, Butler NR. Teenage mothering, admissions to hospital, and accidents during the first 5 years. Arch Dis Child 1983; 58: 6-11.

${ }^{9}$ Langley J, Dodge J, Silva PA. Accidents in the first five years of life: A report from the Dunedin Multidisciplinary Child Development study. Aust Paediatr J 1979; 15: 255-9.
${ }^{10}$ DHSS, OPCS, Welsh Office. Hospital in-patient enquiry reports. London: HMSO.

11 Acheson ED. Medical Record Linkage. London: Oxford University Press, 1967.

${ }^{12}$ Fedrick J. Migration into and out of Oxfordshire in one quarter of 1972. Unit of Clinical Epidemiology. Unpublished paper.

${ }^{13}$ Wadsworth J, Burnell I, Taylor B, Butler N. Family type and accidents in preschool children. $J$ Epidemiol Community Health 1983; 37: 100-4.

${ }^{14}$ Langley J. The "accident prone" child-the perpetration of a myth. Aust Paediatr J 1982; 18: 243-6. 